\title{
CORONALS AND COMPOUNDING IN IRISH
}

Antony D. Green

toniogreen@web.de

October 2004

\begin{abstract}
Irish is characterized by a process of lenition, by which (among other changes) the coronals $t, d$, s become $h, \gamma$, $h$ under certain morphosyntactically determined circumstances. Lenition of coronals is blocked (i.e. $t, d, s$ remain unchanged) after other coronal consonants in certain domains, a phenomenon known as coronal fusion (CF). In a subset of CF domains $s$ changes to $t$ rather than remaining $s$, a phenomenon known as s-fortition. In this paper, it will be shown that the domain of $\mathrm{CF}$ and s-fortition is the (recursive) prosodic word, as these two processes are found in right-headed as well as left-headed compounds, but not in other (noncompound) left-headed complex NPs. An optimality-theoretic analysis reveals that $\mathrm{CF}$ and s-fortition are motivated by the same constraint ranking: the phonological requirement that coronal consonants be followed by other coronal consonants is more important than the selection of the morphologically correct mutation grade of a word.
\end{abstract}

\section{INTRODUCTION}

Like all Insular Celtic languages, Irish (Christian Brothers 1960; Ó Siadhail 1989; Ní Chiosáin 1991; Doyle 2001) is characterized by the phenomenon of initial consonant mutation. This is a phenomenon whereby the initial consonant of a word changes to a different sound under a wide variety of morphosyntactic conditions. Most analyses of the Celtic mutations (Massam 1983; Lieber 1987; Ní Chiosáin 1991; Ball and Müller 1992; Grijzenhout 1995; Kibre 1995; Gnanadesikan 1997; Pyatt 1997) have treated them as phonological rules or processes applying in morphosyntactically determined environments. ${ }^{1}$ Green (2003), on the other hand, argues that the mutations are not part of the phonology at all; rather, mutated and unmutated forms are all listed as input allomorphs, and the correct allomorph is selected in a manner similar to the selection of different case-marked forms.

In this paper, I follow the conclusions of Green (2003), but show that the selection 
of the morphosyntactically correct mutated form can be overridden in some cases by phonological considerations. In particular, the goal of this paper is to analyze exceptional behavior at the contact of two coronals in Irish, where unmutated forms appear in certain circumstances although mutated forms are otherwise expected. It will be shown that a constraint requiring a coronal consonant to be followed by another coronal consonant is responsible for the blocking of lenition at the junction of two coronals and for the exceptional change of $s$ to $t$ (instead of expected $h$ ) in certain environments. A second goal is to show that the difference between left-headed compounds and other head + modifier constructions in Irish is phonological: compounds consist of a single recursive pword while noncompound constructions consist of multiple pwords.

The paper is organized as follows: section 2 provides an introduction to the phenomenon of lenition in Irish, showing both its phonological effects and some of its environments. Section 3 shows the kinds of compounding found in Irish and the conditions under which lenition is expected in each kind of compounding. Section 4 discusses the phenomenon of coronal fusion, according to which lenition of a coronal is blocked if it is preceded by another coronal; I argue that the domain of this phenomenon is the prosodic word. Section 5 discusses s-fortition, a process by which the expected lenition of $s$ to $h$ is replaced by a fortition of $s$ to $t$ in environments very similar to those of coronal fusion. Section 6 provides an analysis in the framework of Optimality Theory (Prince and Smolensky 1993), and section 7 sums up and concludes the paper.

\section{LENITION}

Irish has two productive initial consonant mutations, lenition and eclipsis. In this paper we will be concerned only with lenition. Orthographically lenition is indicated by the letter $\langle\mathrm{h}\rangle$ written after the affected consonant; in the examples in this paper, any Irish 
word whose second letter is $\langle\mathrm{h}\rangle$ may be assumed to have undergone lenition. The phonological effects of lenition, stated broadly, are that stops and $m$ become continuants (fricatives or glides), coronal obstruents $(t, d$, and $s$ ) become laryngeal or dorsal (a phenomenon known as “debuccalization"), and $f$ is deleted. Irish has a persistent phonemic contrast between velarized (so-called "broad") and palatalized (so-called "slender") consonants; in transcription, broad consonants are left unmarked while slender consonants are indicated by the prime $\left({ }^{\prime}\right)$. The effects of lenition in Irish are shown in (1).

\section{(1) Lenition}

\begin{tabular}{|c|c|c|c|c|c|}
\hline \multicolumn{2}{|c|}{ Broad } & \multicolumn{2}{|c|}{ Slender } & \multicolumn{2}{|c|}{ Orthographic } \\
\hline Radical & Lenited & Radical & Lenited & Radical & Lenited \\
\hline $\mathrm{p}$ & $f$ & $\mathrm{p}^{\prime}$ & $\mathrm{f}^{\prime}$ & $\langle p\rangle$ & $\langle\mathrm{ph}\rangle$ \\
\hline $\mathrm{t}$ & $\mathrm{h}$ & $\mathrm{t}^{\prime}$ & $\mathrm{h} \sim \mathrm{x}^{\prime}$ & $\langle t\rangle$ & $\langle$ th $\rangle$ \\
\hline $\mathrm{k}$ & $x$ & $\mathrm{k}^{\prime}$ & $\mathrm{x}^{\prime}$ & $\langle c\rangle$ & $\langle\mathrm{ch}\rangle$ \\
\hline $\mathrm{b}$ & $\mathrm{W} \sim \mathrm{V}$ & $\mathrm{b}^{\prime}$ & $\mathrm{V}^{\prime}$ & $\langle b\rangle$ & $\langle\mathrm{bh}\rangle$ \\
\hline d & 8 & $\mathrm{~d}^{\prime}$ & $\mathrm{j} \sim \mathrm{y}^{\prime}$ & $\langle\mathrm{d}\rangle$ & $\langle\mathrm{dh}\rangle$ \\
\hline g & Y & $g^{\prime}$ & $\mathrm{j} \sim \mathrm{y}^{\prime}$ & $\langle\mathrm{g}\rangle$ & $\langle\mathrm{gh}\rangle$ \\
\hline $\mathrm{f}$ & $\varnothing$ & $\mathrm{f}^{\prime}$ & $\varnothing$ & $\langle\mathrm{f}\rangle$ & $\langle\mathrm{fh}\rangle$ \\
\hline $\mathrm{S}$ & $\mathrm{h}$ & $\mathrm{s}^{\prime}$ & $\mathrm{h} \sim \mathrm{x}^{\prime}$ & $\langle\mathrm{s}\rangle$ & $\langle\mathrm{sh}\rangle$ \\
\hline $\mathrm{m}$ & $\mathrm{W} \sim \mathrm{V}$ & $\mathrm{m}^{\prime}$ & $\mathrm{v}^{\prime}$ & $\langle\mathrm{m}\rangle$ & $\langle\mathrm{mh}\rangle$ \\
\hline
\end{tabular}

As mentioned above, the environments in which lenition applies are generally held to be morphosyntactic, not phonological. For example, nouns are lenited after certain proclitics, as shown in (2), but not after others, as shown in (3). 
(2) Lenition of nouns after certain proclitics
a. peann 'pen'
mo pheann
'my pen'
b. bróg 'shoe'
an bhróg
'the shoe'
c. cat
'cat'
an chait
'the cat (gen.)'

(3) No lenition after other proclitics
a. peann 'pen'
a peann
'her pen'
b. bróige 'shoe (gen.)'
na bróige
'the shoe (gen.)'
c. cat
'cat'
an cat
'the cat'

Another environment in which lenition is found is definite nouns and noun phrases used genitivally, as shown in (4).

(4) Lenition of a definite noun or noun phrase used genitivally
a. Máire
'Mary'
b. bróg [Mháire]
'Mary's shoe'
c. sáil [bhróg Mháire] 'the heel of Mary's shoe'

Lenition is found on an attributive adjective after a noun that is either (i) feminine singular or (ii) plural and ending in a slender consonant (indicated orthographically by the presence of $\langle i\rangle$ immediately before the consonant or consonant cluster). This pair of conditions will frequently recur in the following discussion, and will henceforth be referred to as "conditions (i) and (ii)". Examples are shown in (5). 
(5) Lenition of an attributive adjective after a noun that is in either of conditions (i) and (ii)

a. Condition (i): Feminine singular bróg FEM.SG $_{\text {mór }} \quad$ 'a large shoe'

b. Condition (ii): Plural ending in a slender consonant fir $_{\mathrm{PL}}$ mhóra 'large men'

There is no lenition of an attributive adjective after a masculine singular nominative noun or after a plural noun that does not end in a slender consonant, as shown in (6).

(6) No lenition of an attributive adjective after a noun that is not in either of conditions (i) and (ii)
a. fear $_{\mathrm{MASC} . S G}$ mór 'a large man'
b. bróga ${ }_{\mathrm{PL}}$ móra 'large shoes'

There are many other environments of lenition as well; the interested reader is referred to Christian Brothers (1960) for a comprehensive list or to the appendix of Green (2003) for a representative list. One final environment in which Irish has lenition is in compounds, to which we now turn our attention.

\section{COMPOUNDING IN IRISH}

Irish has two kinds of nominal compound, left-headed and right-headed. Some descriptive grammars, e.g. Christian Brothers (1960), consider only right-headed compounds to be true compounds, treating left-headed compounds instead as a kind of phrase. But as we shall see in this section, there are differences between head + modifier phrases and left-headed compounds, so the distinction between the two is justified, and recognized as such by other descriptive grammars such as Doyle (2001). The 
uncontroversial right-headed compounds have the following characteristics: the second member is inflected for case and number while the first member remains uninflected; the second member undergoes lenition, no matter what first member is; and the compound is orthographically written as one word. Some examples of right-headed compounds are shown in (7).

(7) Examples of right-headed compounds

a. ainm 'name' + focal 'word' = ainmfhocal 'noun' ainmfhocail genitive singular/nominative plural

b. breis 'increase' + céim 'degree' = breischéim 'comparative degree' breischéime genitive singular breischéimeanna nominative plural

The prosodic structure of right-headed compounds may fairly uncontroversially be assumed to involve a recursive prosodic word (pword, symbolized $\omega$ ) dominating two lower pwords, thus ${ }_{\omega}\left(\omega_{\omega}(\right.$ ainm $) \omega_{\omega}($ fhocal $\left.)\right) \omega_{\omega}\left(\omega_{\omega}(\right.$ breis $) \omega_{\omega}($ chéim $\left.)\right)$, etc. Nespor and Vogel (1986: 122-40) analyze compounds in Hungarian, Italian, and Dutch as containing two pwords, but do not assume a higher recursive pword. The view that the two pwords of a compound are incorporated into a higher pword has been advocated by Booij (1988), Inkelas (1989), McHugh (1990), and McCarthy and Prince (1993a, 1993b) among others.

The characteristics of left-headed compounds are these: the second member is in the genitive, while the first member is inflected for number only; the second member is lenited only if the first member meets one of conditions (i) and (ii); orthographically a 
left-headed compound is written as two words. Some examples of left-headed compounds with lenition (because condition (i) or (ii) has been met) are shown in (8), related forms without lenition are shown in (9).

(8) Examples of left-headed compounds with lenition in conditions (i) and (ii)

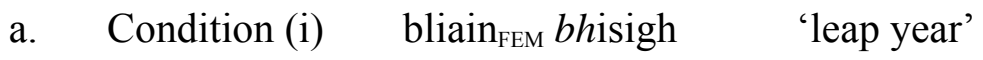 year of-increase
b. Condition (ii) éisc mhara 'sea-fish (plural)' fish (pl.) of-sea

(9) Examples of left-headed compounds without lenition (conditions (i) and (ii) not met)
a. blianta $\mathrm{PL}_{\mathrm{PL}}$ bisigh 'years of-increase' $\quad=\quad$ 'leap years'
b. $\quad$ iasc $_{\mathrm{MASC}}$ mara 'fish (sg.) of-sea' = 'sea-fish' (singular)

Left-headed compounds look very similar to other head + modifier NPs (noun + indefinite genitive and noun + adjective) like those in (10), which also show lenition only under conditions (i) and (ii).

(10) Head + modifier NPs (noun + indefinite genitive, noun + adjective); lenition in conditions (i) and (ii)

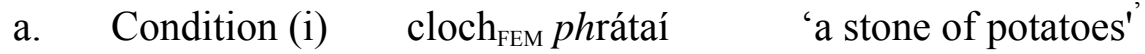
b. Condition (ii) buidéil $1_{\mathrm{PL}}$ bhainne 'bottles of milk'

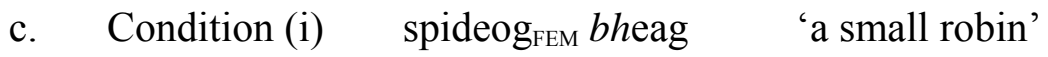
d. Condition (ii) fir fir $_{\mathrm{PL}}$ mhóra 'large men'

Despite the surface similarities between the left-headed compounds in (8) and the noncompound head + modifier NPs in (10), there are differences between them. I assume that the differences can be ascribed to a difference in prosodic structure. 
Namely, compounds like those in (8) have a recursive pword, e.g. $\omega_{(}$(bliain) ${ }_{\omega}($ bhisigh $\left.)\right)$, while noncompound head + modifier NPs like those in (10) are simple strings of pwords within a phonological phrase (symbolized $\varphi)$, e.g. $\varphi\left(\omega_{\omega}(\operatorname{cloch})\right.$

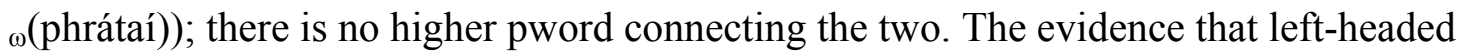
compounds are different from noncompound head + modifier NPs is, firstly, that in compounds but not other complex NPs, lenition is blocked when two coronals come in contact $^{2}$, and secondly, that in compounds but not other complex NPs, $s$ undergoes fortition to $t$ rather than lenition to $h$ after $n$ or $l$ in some dialects. The first phenomenon is known as coronal fusion and is discussed in section 4; the second, known as sfortition, in section 5 .

\section{CORONAL FUSION}

Ní Chiosáin (1991) states coronal fusion (henceforth CF) as a rule, stated in (11), that makes adjacent coronals share a single place node. The resulting structure is then immune to rules causing lenition because of geminate inalterability (Guerssel 1977; Hayes 1986; Schein and Steriade 1986; Inkelas and Cho 1993; Kirchner 2000).

(11) Coronal fusion

Place Place

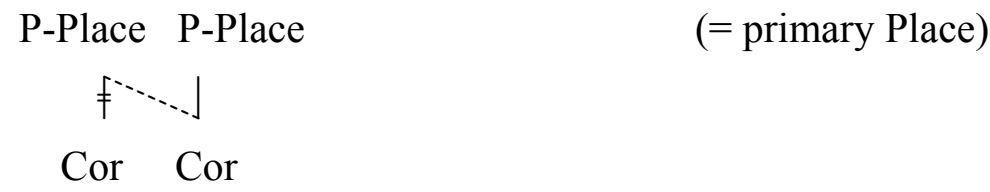

As for the environments in which CF applies, Ní Chiosáin (1991: 108) states, "adjacent heteromorphemic coronal consonants undergo coronal fusion in certain wordformation domains, namely, in compounds and prefixed forms as well as in a clitic domain.” Some examples of CF applying in environments where lenition would 
otherwise be expected are shown in (12). In all of these cases we may assume a recursive pword.

(12) Environments of CF where lenition is expected

a. Right-headed compound

$$
\begin{gathered}
\omega\left(\omega_{\omega}(\text { ard }){ }_{\omega}(\text { sagart })\right) \\
\text { high priest }
\end{gathered}
$$

b. Left-headed compound

$$
\begin{aligned}
& \omega\left(\omega_{\omega}\left(\text { tonn }_{\text {FEM }}\right) \omega(\text { tuile })\right) \\
& \text { wave flood-GEN }
\end{aligned}
$$

c. Prefix + root

$$
\begin{gathered}
\omega\left(\omega(\text { an }){ }_{\omega}(\text { deas })\right) \\
\text { very nice }
\end{gathered}
$$

d. Proclitic + host

$$
\begin{aligned}
& \left.\left.\omega\left(\text { an }_{\omega} \text { (tairbh }\right)\right) \quad \text { 'the bull' (gen. sg. }\right)^{3} \\
& \text { the bull-GEN }
\end{aligned}
$$

In other leniting environments, crucially including noncompound complex NPs,

$\mathrm{CF}$ is not found; thus lenition is not blocked but applies regularly. We may assume that in these cases there is no recursive pword and that therefore the (recursive) pword is the domain of CF. Examples are shown in (13).

(13) No CF (i.e. lenition is not blocked):

a. Definite NPs used genitivally

$$
\begin{aligned}
& { }_{\omega}(\text { díon })_{\omega}(\text { shiopa }) \omega_{\omega}\left(\text { an }{ }_{\omega}(\text { bhúistéara })\right) \\
& \text { roof shop the butcher-GEN } \\
& \text { 'the roof of the butcher's shop' } \\
& { }_{\omega}(\text { foireann }){ }_{\omega}(\text { Dhoire }) \\
& \text { team Derry-GEN } \\
& \text { 'the Derry team' }
\end{aligned}
$$


b. Indefinite genitives in conditions (i) and (ii)

$$
\begin{aligned}
& \omega_{\omega}\left(\text { milseach } t_{\mathrm{FEM}}\right)_{\omega}(\text { shiúcra }) \\
& \text { sweetness sugar-GEN } \\
& \text { 'the sweetness of sugar' } \\
& \text { (buidéil) }{ }_{\omega}(\text { shú }) \\
& \text { bottles juice-GEN } \\
& \text { 'bottles of juice' }
\end{aligned}
$$

c. Attributive adjectives in conditions (i) and (ii)

$$
\begin{aligned}
& \omega\left(\cos _{\mathrm{FEM}}\right)_{\omega}(\text { thinn }) \\
& \text { leg sore } \\
& \text { 'a sore leg' } \\
& \omega_{\omega}\left(\text { eitleáin } n_{\mathrm{PL}}\right)_{\omega}(\text { dhearga }) \\
& \text { airplanes red-PL } \\
& \text { 'red airplanes' }
\end{aligned}
$$

If the prosodic structures of (12) and (13) are correct, then the domain of CF is the pword: CF applies (blocking lenition) inside recursive pwords, as shown in (14), while $\mathrm{CF}$ is blocked (allowing lenition to apply) between pwords whose next highest level is the phonological phrase, as shown in (15). Recall that the lenition of coronals is manifested by debuccalization, interpreted by Ní Chiosáin (1991) as the delinking of the coronal node.

(14) Coronal fusion (lenition blocked) inside recursive pwords

$$
\begin{gathered}
\omega_{\omega}\left(\omega_{\omega}(\operatorname{ard}){ }_{\omega}(\text { sagart })\right) \\
{ }_{\omega}^{\text {Coronal }}\left({ }_{\omega}(\text { an }){ }_{\omega}(\text { deas })\right) \\
\text { Coronal }
\end{gathered}
$$$$
\omega(\omega(\text { tonn }) \omega(\text { tuile }))
$$$$
\text { Coronal }
$$$$
\omega_{\omega}\left(\text { an }{ }_{\omega}(\text { tairbh })\right)
$$$$
\text { Coronal }
$$

(15) No coronal fusion (lenition applies) between pwords within p-phrase

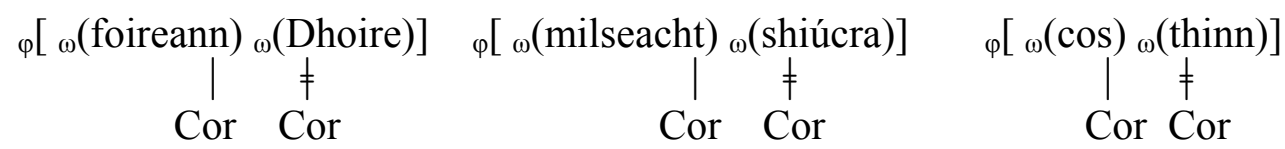


Thus, the fact that left-headed compounds like tonn tuile 'tidal wave' are subject to CF, while noncompound head + modifier NPs like foireann Dhoire 'the Derry team' are not, is evidence that the two have different prosodic structures. The compound tonn tuile is parsed into a higher recursive pword, while the noncompound foireann Dhoire is not. The other phenomenon that separates the two is s-fortition, discussed in the next section.

\section{S-FORTITION}

S-fortition is the process by which $s$ becomes $t$ (orthographic $\langle\mathrm{ts}\rangle$ ) after $n$ and sometimes l. S-fortition occurs only in environments where lenition of noncoronals and CF of $t, d$ would be expected. In the standard language, the only environment of s-fortition is in leniting environments after the definite article, as illustrated in (16).

(16) S-fortition after the definite article (only environment in the standard language) an tsagairt [ən tagərt'] 'the priest' (masc. sg. gen.) an tseachtain [ən t'axtən'] 'the week' (fem. sg. nom.) don tsagart [don tagərt] 'to the priest' (masc. sg. dat.) ${ }^{4}$ den tseachtain [d'en t'axtən'] 'of the week' (fem. sg. dat.)

Outside the standard, s-fortition is found variably after $n$ and $l$ in any environment where lenition of noncoronals and CF of $t, d, s$ is found in the standard language, cf. (12). Examples are shown in (17).

(17) Nonstandard: s-fortition (variably) after $n, l$ in the same environments as $\mathrm{CF}$ a. Right-headed compound

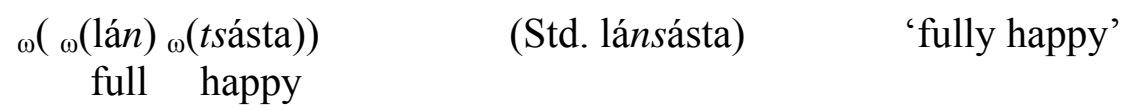




$$
\begin{aligned}
& \left.\omega_{\omega}^{\left({ }_{\omega}(\text { cúl }){ }_{\omega}(\text { tseomra })\right)} \quad \text { (Std. cúlseomra }\right) \quad \text { 'back room’ } \\
& \text { back room }
\end{aligned}
$$

b. Left-headed compound in conditions (i) and (ii)

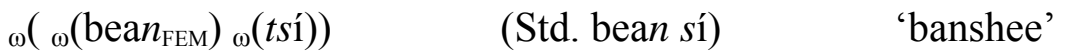

$$
\begin{aligned}
& \text { woman fairy mound-GEN } \\
& { }_{\omega}\left(\omega_{\omega}\left(\operatorname{scoil}_{\mathrm{FEM}}\right)_{\omega}(\text { tsaothair })\right) \quad \text { (Std. scoil saothair) 'industrial school' }
\end{aligned}
$$

c. Prefix + root

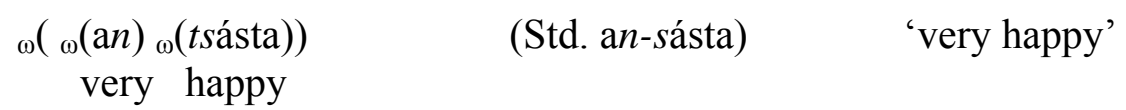

d. Proclitic + host

$$
\begin{aligned}
& \omega_{\omega}\left(\text { aon }{ }_{\omega}(\text { tseans })\right) \\
& \text { any chance }
\end{aligned}
$$

In environments where CF does not apply, such as noncompound complex NPs (cf. (13)), s-fortition also does not apply, so that the regular lenition of $s$ to $h\langle\mathrm{sh}\rangle$ is found, as shown in the examples in (18).

(18) No s-fortition in leniting environments where there's also no CF, e.g. noncompound complex NPs

a. Definite NPs used genitivally

$$
\begin{aligned}
& \omega(\text { díon }){ }_{\omega}(\text { shiopa }){ }_{\omega}\left(\text { an }_{\omega} \text { (bhúistéara }\right) \\
& \text { roof shop the butcher-GEN }
\end{aligned}
$$

'the roof of the butcher's shop'

$$
\begin{aligned}
& \text { ¡(asal) })_{\omega}(\text { Sheáin }) \\
& \text { donkey Seán-GEN } \\
& \text { 'Seán’s donkey’ }
\end{aligned}
$$

b. Indefinite genitives in conditions (i) and (ii)

$$
\begin{aligned}
& { }_{\omega}\left(\text { maidin }_{\text {FEM }}\right)_{\omega}(\text { shamhraidh }) \\
& \text { morning summer-GEN } \\
& \text { 'a summer morning' }
\end{aligned}
$$



( $($ buidéil $){ }_{\omega}($ shú $)$
bottles juice-GEN
'bottles of juice'

c. Attributive adjectives in conditions (i) and (ii)

$$
\begin{aligned}
& { }_{\omega}\left(\text { bea }_{\mathrm{FEM}}\right){ }_{\omega}(\text { shaolta }) \\
& \text { woman worldly } \\
& \text { 'a worldly woman' } \\
& { }_{\omega}(\text { focail }){ }_{\omega}(\text { shéimhe }) \\
& \text { words mild-PL } \\
& \text { 'mild words' }
\end{aligned}
$$

To sum up, we may conclude that the domain of both CF and s-fortition is the (recursive) pword. Left-headed compounds like tonn tuile 'tidal wave', bean (t)sí 'banshee', and scoil (t)saothair 'industrial school' have a recursive pword and are thus subject to CF and s-fortition, while noncompound head + modifier constructions like foireann Dhoire ‘the Derry team', asal Sheáin 'Seán’s donkey’, maidin shamhraidh 'a summer morning', and bean shaolta 'a worldly woman' have no recursive pword and thus have regular lenition. Having established the facts, we can move on in the next section to an analysis, developed within the framework of Optimality Theory.

\section{AN OT ANALYSIS}

\subsection{WHICH MUTATION GRADE IS THE OPTIMAL CANDIDATE?}

Usually a phonological alternation is analyzed in OT as the result of a constraint interaction requiring one allophone to surface in some environments and another allophone to surface in other environments. For example, the $t / d$ alternation found in German [ra:t/ra:dəs] 'wheel nom./gen.' is ascribed to a constraint hierarchy forbidding voiced obstruents in coda position but allowing them to surface faithfully in onset position. But Green (2003) argues that the Celtic initial consonant mutations, including 
Irish lenition, are not phonological processes at all, but rather separate lexical entries selected by subcategorization. Thus the input/output relationship is not that shown in (19), where the different outputs are optimal in different environments, but rather that shown in (20), where the inputs are allomorphs related to each other through their semantics and their phonological similarity.

(19) Incorrect input/output relationship for radical peann and lenited pheann 'pen'

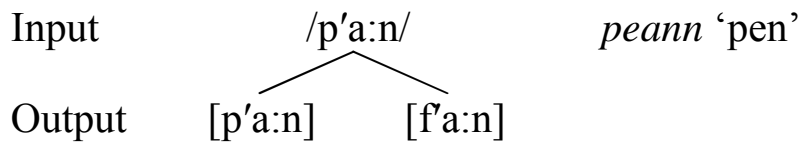

(20) Correct input/output relationship for radical peann and lenited pheann 'pen' Input
Output
[p'a:n]

The choice between them is made by subcategorization: the proclitic mo 'my', for example, is marked to take the lenition form of the noun it governs. The relationship between the mutation trigger (e.g. mo 'my') and target (e.g. pheann 'pen, lenited') is governed by the constraint MutATiOn AgREEMEnT (MutAgreE), which states that trigger and target must agree in their mutation grade. Since the lenited [f'a:n] corresponds to input /f'a:n/, rather than input /p'a:n/, there is no violation of faithfulness (specifically, IDENT(cont), requiring an output segment to have the same specification for the feature [continuant] as its input correspondent) when lenition occurs. This is shown by the tableau in (21). 
(21) No violation of faithfulness under lenition, from mo pheann 'my pen'

\begin{tabular}{|r||c:c|}
\hline$/$ mo $_{\text {LEN }}+\left\{\mathrm{p}^{\prime} \mathrm{a}: \mathrm{n}_{\mathrm{RAD}}\right.$, & MUTAGREE & IDENT(cont) \\
$\left.\mathrm{f}^{\prime} \mathrm{a}: \mathrm{n}_{\mathrm{LEN}}\right\} /$ & & \\
\hline \hline mə p'a:n & $* !$ & \\
\hline \hline mə f'a:n & & \\
\hline
\end{tabular}

Under normal circumstances, MUTAGREE is sufficient to determine the mutation grade of the surface form, but when two coronals come in contact within a recursive pword, special considerations come into play, triggering either CF or s-fortition.

\subsection{CORONAL FUSION}

The rule of coronal fusion given in (11) can be restated as an OT markedness constraint CORONAL HOMORGANICITY (CORHOM), as in (22).

(22) Coronal Homorganicity (CORHom)

Within $\omega$, a coronal consonant shares a place of articulation with a following consonant.

The effect of CORHOM in Irish is not immediately apparent since there are a number of words in which coronal consonants are followed by noncoronal consonants, as shown in (23).

(23) Coronal + noncoronal clusters

\begin{tabular}{|c|c|c|}
\hline admhaigh & [adwi:] & 'admit' \\
\hline olc & {$[\mathrm{olk}]$} & 'bad' \\
\hline dualgas & [duəlgəs] & 'duty' \\
\hline ceolmhar & [k'o:lwər] & 'musical' \\
\hline greannmhar & [g'r'a:nwə & 'funny' \\
\hline
\end{tabular}




$\begin{array}{lll}\text { briosca } & {\left[\mathrm{b}^{\prime} \mathrm{r}^{\prime} \text { isk }\right]} & \text { 'biscuit, cookie' } \\ \text { smaoineamh } & {[\text { smi:n'əv }]} & \text { 'thought' } \\ \text { aspal } & {[\text { aspəl }]} & \text { 'apostle' }\end{array}$

The data in (23) force us to conclude that CORHOM is ranked below FAITH(Place) in Irish, so that a noncoronal consonant in the input cannot surface as a coronal in order to meet CORHOM.

(24) $\operatorname{FAITH}($ Place) $\gg$ CORHOM

\begin{tabular}{|r||c|c|}
\hline$/$ olk/ & FAITH(Place) & CORHOM \\
\hline \hline$\omega_{\omega}($ olk $)$ & & $*$ \\
\hline$\omega($ olt $)$ & $* !$ & \\
\hline
\end{tabular}

But if two allomorphs are available, as is the case with the mutations, CORHOM can force the selection of the homorganic one, because as long as the output is faithful to one of the input allomorphs, there is no violation of faithfulness. In Irish, CORHOM outranks MUTAGREE, so that a coronal-initial allomorph is selected after a coronal rather than the allomorph with the correct mutation. In other words, the mutation is suppressed in order to fulfill CORHOM. This is illustrated in (25) for the compound seanduine 'old person': the form sean is marked [+LEN] because ordinarily its complement must be lenited (e.g. seanbhean 'old woman'). But if the complement begins with a coronal, then the radical is selected so that CORHOM can be fulfilled.

(25) CORHOM $\gg$ MutAgreE, from seanduine 'old person'

\begin{tabular}{|c|c|c|c|}
\hline $\begin{array}{r}/ \mathrm{s}^{\prime} \mathrm{an}_{+\mathrm{LEN}}+\left\{\operatorname{din}^{\prime} \partial_{\mathrm{RAD}},\right. \\
\left.\operatorname{yin}^{\prime} \partial_{\mathrm{LEN}}\right\}\end{array}$ & FAITH(Place) & CORHOM & MuTAGREE \\
\hline${ }_{\omega}\left({ }_{\omega}\left(\operatorname{s}^{\prime} a n\right)_{\omega}\left(\operatorname{din}^{\prime} \partial\right)\right)$ & & & * \\
\hline$\omega\left(\omega\left(\right.\right.$ s'an $_{\omega}\left(\right.$ yin'$\left.\left.^{\prime} \partial\right)\right)$ & & $* !$ & \\
\hline
\end{tabular}


However, where no homorganic allomorph is available, MUTAGREE decides in favor of the lenited allomorph, as shown in (26) for seanghoimh 'old sore'. The allomorphs of goimh are radical [giv'] and lenited [ðiv']; neither begins with a coronal. This being the case, CORHOM cannot decide between them, and high-ranking FAITH(Place) blocks unfaithful [div'], so low-ranking MUTAGREE makes the decision in favor of the lenited allomorph [yiv'].

(26) MutAgreE decides when CORHom cannot be met, from seanghoimh 'old sore'

\begin{tabular}{|c|c|c|c|}
\hline $\begin{array}{r}/ \mathrm{s}^{\prime} \mathrm{an}_{+\mathrm{LEN}}+\left\{\operatorname{giv}_{\mathrm{RAD}}^{\prime},\right. \\
\left.\operatorname{\gamma iv}_{\mathrm{LEN}}^{\prime}\right\}\end{array}$ & FAITH(Place) & CORHOM & MutAGREE \\
\hline$\omega\left(\omega\left(s^{\prime} a n\right){ }_{\omega}\left(g^{\prime} v_{\text {RAD }}^{\prime}\right)\right)$ & & $*$ & $* !$ \\
\hline${ }_{\omega}\left(\omega\left(\mathrm{s}^{\prime} \mathrm{an}\right){ }_{\omega}\left(\mathrm{yiv}_{\mathrm{LEN}}^{\prime}\right)\right)$ & & $*$ & \\
\hline$\omega\left(\omega\left(s^{\prime} a n\right){ }_{\omega}\left(\operatorname{div}_{\mathrm{RAD}}^{\prime}\right)\right)$ & $* !$ & & * \\
\hline
\end{tabular}

As stated in (22), the domain of CORHOM is the pword. As a result, a pword-final coronal followed by a pword-initial noncoronal does not engender a violation of CORHom unless the two pwords are incorporated into a recursive pword. This is the case with right-headed and left-headed compounds ((27) and (28) respectively), but not with other complex NPs (29). Thus lenition is blocked in both kinds of compounds but not in noncompound phrases.

(27) CORHOM applies within pword: right-headed compound ardsagart 'high priest'

\begin{tabular}{|r||c|c|}
\hline $\begin{array}{r}\text { /a:rd }{ }_{\text {LEN }}+\left\{\text { sagərt }_{\text {RAD }},\right. \\
\left.\text { hagərt }_{\text {LEN }}\right\}\end{array}$ & CORHOM & MUTAGREE \\
\hline$\omega_{\omega}\left(\omega(\text { a:rd })_{\omega}(\right.$ sagərt $\left.)\right)$ & & $*$ \\
\hline$\omega_{\omega}(\text { (a:rd })_{\omega}($ hagərt $\left.)\right)$ & $* !$ & \\
\hline
\end{tabular}


(28) CORHOM applies within pword: left-headed compound tonn tuile 'tidal wave'

\begin{tabular}{|c|c|c|}
\hline $\begin{array}{r}/ \text { tu: } n_{+\mathrm{LEN}}+\left\{\text { till' }^{\prime} \partial_{\mathrm{RAD}}\right. \\
\left.\text { hil }^{\prime} \partial_{\mathrm{LEN}}\right\} /\end{array}$ & CORHOM & MUtAGREE \\
\hline${ }_{\omega}\left(\omega_{\omega}(\mathrm{tu}: \mathrm{n}){ }_{\omega}\left(\mathrm{til}^{\prime} \partial\right)\right)$ & & $*$ \\
\hline${ }_{\omega}\left(\omega(\text { tu:n })_{\omega}\left(\right.\right.$ hil'əo $\left.\left.^{\prime}\right)\right)$ & $* !$ & \\
\hline
\end{tabular}

(29) CORHOM does not apply outside pword: noncompound foireann Dhoire 'the Derry team'

\begin{tabular}{|c|c|c|}
\hline $\begin{array}{r}/ \text { fer'ən }_{+\mathrm{LEN}}+\left\{\operatorname{der}^{\prime} \partial_{\mathrm{RAD}},\right. \\
\left.\operatorname{\gamma er}^{\prime} \partial_{\mathrm{LEN}}\right\} /\end{array}$ & CORHOM & MutAGREE \\
\hline$\varphi\left[\omega\left(\right.\right.$ fer $\left.\left.^{\prime} \partial n\right){ }_{\omega}\left(\operatorname{der}^{\prime} \partial\right)\right]$ & & $* !$ \\
\hline$\varphi_{\varphi}\left[\omega\left(\text { fer}^{\prime} \partial n\right)_{\omega}\left(\right.\right.$ yer $\left.\left.^{\prime} \partial\right)\right]$ & & \\
\hline
\end{tabular}

The facts of CF, analyzed here as the interaction between CORHOM and MUtAgREE, thus provide evidence that left-headed compounds like tonn tuile contain a recursive pword while noncompound complex NPs like foireann Dhoire do not. In the next section we analyze s-fortition, which provides additional evidence for the same conclusion.

\subsection{S-FORTITION}

As we saw above in $\S 5$, s-fortition is the change of $s$ to $t\langle\mathrm{ts}\rangle$ in lenition environments after $n$ and $l$ within a (recursive) pword. Because s-fortition occurs only in lenition environments, we may assume that the t-initial forms are also lenition allomorphs. Thus an s-initial word like sagart 'priest' has not one lenition allomorph in the input, but rather two: /hagərt/ and /tagərt/. ${ }^{5}$ The t-initial allomorphs occur only after $n$ and $l$, not after other coronals. Examples are shown in (30). 
(30) t-initial lenition forms only after $n$ and $l$
a. $\quad \omega\left(\omega_{\omega}(\right.$ lán $) \omega_{\omega}($ tsásta $\left.)\right)$
full happy
'fully happy'
b. $\omega_{\omega}\left(\omega_{\omega}(\right.$ scoil $){ }_{\omega}($ tsaothair $\left.)\right)$ school industry-GEN
'industrial school'
c. $\omega_{\omega}\left(\omega_{(\operatorname{ard})} \omega_{\omega}(\right.$ sagart $\left.)\right)$
high priest
$*_{\omega}$ (tsagart)
'high priest'
d. $\omega_{\omega}\left(\omega^{(\cos )}{ }_{\omega}(\right.$ slua $)$
foot army
$*_{\omega}($ tslua $)$
'infantry'

In (30)a-b the t-initial allomorph is selected because it allows both CORHOM and MutAGREE to be met. The form [la:nsa:stə], with the radical of sásta, would violate MutAGREE, and [la:nha:stə], with the h-initial lenition allomorph, would violate CorHom, as shown in the tableau in (31).

(31) t-initial lenition forms selected after $n$ and l, from lántsásta 'fully happy'

\begin{tabular}{|c|c|c|c|c|c|}
\hline 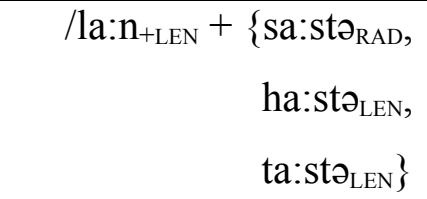 & CORHOM & *SON+FRIC & $\begin{array}{l}\text { IDENT } \\
\text { (cont) }\end{array}$ & DEP(Cor) & MUTAGREE \\
\hline 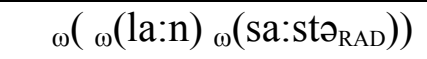 & & $* !$ & & & $*$ \\
\hline$\omega\left(\omega(\text { la:n })_{\omega}\left(\right.\right.$ ha:stə $\left.\left.\partial_{\text {LEN }}\right)\right)$ & $* !$ & $*$ & & & \\
\hline${ }_{\omega}\left(\omega_{\omega}(\mathrm{la}: \mathrm{n})_{\omega}\left(\right.\right.$ ta:stว $\left.\left.\partial_{\mathrm{LEN}}\right)\right)$ & & & $*$ & $*$ & \\
\hline
\end{tabular}

A problem arises, however, in limiting the selection of the t-initial lenition allomorphs to the position after coronal sonorants. As we saw in $(30) \mathrm{c}-\mathrm{d}$, the s-initial radical allomorph is selected after coronal obstruents: [a:rdsagərt] 'high priest', [kossluə] 'infantry'. This is unexpected, since the competing candidates *[a:rdtagərt] and *[kostluə] meet both CorHom and MutAgreE, while the optimal candidates violate MUTAGREE. There must be some higher constraint the losing candidates violate. The first option to consider is a phonological constraint. If obstruent + fricative 
sequences are universally less marked than obstruent + stop sequences, then we could have an explanation for the selection of [a:rdsagərt] and [kossluə] rather than *[a:rdtagərt] and *[kostluə]. Since the sequences in question always cross a syllable boundary, and since an obvious difference between stops and fricatives is the difference in sonority, we may look to the Syllable Contact Law (Murray \& Vennemann 1983; Vennemann 1988), which requires an onset consonant to be less sonorant than a preceding coda consonant, to provide an answer. Unfortunately, the SCL is violated by both stop + stop and stop + fricative sequences, so it cannot decide between [a:rd.sagərt] and *[a:rd.tagərt]. Moreover, the SCL is violated by fricative + fricative sequences but obeyed by fricative + stop sequences, so it falsely predicts *[kos.tluə] to be better than [kos.sluə]. ${ }^{6}$ Apart from the issue of syllable contact, stops are less marked than fricatives not only in an absolute sense (stops occurring crosslinguistically more frequently than fricatives and being acquired by children earlier than fricatives), but also specifically in syllable onset position (Vennemann 1988). So both context-sensitive and context-insensitive markedness considerations falsely predict the t-initial forms to be preferred to the s-initial forms.

Thus it seems no phonological constraint can rule out *[a:rd.tagərt] and *[kos.tluə]. Rather, a morphological alignment constraint tX-TO-CORSON is necessary, requiring a t-initial lenition allomorph to follow a coronal sonorant. ${ }^{7}$

(32) tX-TO-CORSON

$\operatorname{Align}\left(\mathrm{tX}_{\mathrm{LEN}}, \mathrm{L} ;[+\right.$ son, COR], R)

The left edge of every t-initial lenition allomorph is aligned with the right edge of some coronal sonorant.

The effect of tX-TO-CORSON is shown for ardsagart 'high priest' by the tableau in (33). 
(33) s-initial lenition forms selected after coronal obstruents, from ardsagart 'high priest'

\begin{tabular}{|r||c|c|c|}
\hline $\begin{array}{r}\text { /a:rd }{ }_{\text {LEN }}+\left\{\text { sagərt }_{\text {RAD }},\right. \\
\text { hagərt }_{\text {LEN }}, \\
\left.\text { tagərt }_{\text {LEN }}\right\}\end{array}$ & CORHOM & tX-TO-CORSON & MUTAGREE \\
\hline \hline$\omega_{\omega}(\mathrm{a}: \mathrm{rd})_{\omega}\left(\right.$ sagərt $\left._{\mathrm{RAD}}\right)$ & & & \\
\hline$\omega\left(\omega(\mathrm{a}: \mathrm{rd})_{\omega}\left(\right.\right.$ hagərt $\left._{\mathrm{LEN}}\right)$ & $* !$ & & $*$ \\
\hline$\omega\left(\omega(\mathrm{a}: \mathrm{rd})_{\omega}\left(\right.\right.$ tagərt $\left._{\mathrm{LEN}}\right)$ & & $* !$ & \\
\hline
\end{tabular}

As discussed above, the domain of CORHOM is the pword, crucially including the recursive pword. In noncompound complex NPs, i.e. where there is no recursive pword, or where the first word does not end in a coronal, CORHOM does not apply. Similarly, CORHom does not apply if the first member of a compound ends in a noncoronal. In these cases, the choice between the h-initial and the t-initial lenition allomorphs is made by the fact that glottals are crosslinguistically less marked than coronals (Lombardi 2002), stated by the universal constraint ranking $*$ COR $\gg * h$. This is illustrated in the tableaux in (34)-(35), where however only relevant violations of *COR and *h are listed.

(34) h-initial allomorph in noncompound NP: bean Shéamais 'Séamas's wife'

\begin{tabular}{|c|c|c|c|}
\hline $\begin{array}{r}/ \mathrm{b}^{\prime} \mathrm{an}+_{\mathrm{LEN}}\left\{\mathrm{s}^{\prime} \mathrm{e}: \mathrm{məs}_{\mathrm{RAD}}^{\prime}\right. \\
\text { he:məs}{ }_{\mathrm{LEN}}^{\prime}, \\
\left.\text { te:məs}{ }_{\mathrm{LEN}}^{\prime}\right\} /\end{array}$ & MutAGREE & $* \mathrm{COR}$ & $* \mathrm{~h}$ \\
\hline$\left.\varphi_{\varphi[\omega}\left(\mathrm{b}^{\prime} \mathrm{an}\right){ }_{\omega}\left(\mathrm{s}^{\prime} \mathrm{e}: \mathrm{m}^{\prime} \mathrm{s}^{\prime}\right)\right]$ & $* !$ & * & \\
\hline${ }_{\varphi}\left[\omega_{\omega}\left(\mathrm{b}^{\prime}\right.\right.$ an $){ }_{\omega}($ he:məs') $]$ & & & * \\
\hline$\varphi_{\varphi}\left[\omega\left(\mathrm{b}^{\prime} \mathrm{an}\right){ }_{\omega}\left(\mathrm{t}^{\prime} \mathrm{e}: \mathrm{məs}^{\prime}\right)\right]$ & & $* !$ & \\
\hline
\end{tabular}


(35) h-initial allomorph after noncoronal: droch 'bad' + saol 'life' $\rightarrow$ drochshaol 'a hard life'

\begin{tabular}{|r||c|c|c|}
\hline$/$ drox $_{+ \text {LEN }}\left\{\right.$ si: $1_{\text {RAD }}$, & IDENT(cont) & DEP(Cor) & MUTAGREE \\
hi: $1_{\text {LEN }}$, & & & \\
ti: $\left.1_{\text {LEN }}\right\} /$ & & & \\
\hline$\omega\left(\omega(\text { drox })_{\omega}(\right.$ si:l $\left.)\right)$ & & & $* !$ \\
\hline$\omega\left(\omega(\text { drox })_{\omega}(\right.$ hi:l $\left.)\right)$ & & & \\
\hline$\omega\left(\omega(\text { drox })_{\omega}(\right.$ ti:l $\left.)\right)$ & $* !$ & $*$ & \\
\hline
\end{tabular}

In this section we have seen how an OT analysis enables us to unify the phenomena of

$\mathrm{CF}$ and s-fortition: both processes result from the ranking CORHOM $\gg$ MutAgreE, i.e. it is more important to have a coronal consonant followed by another coronal consonant (where one is available) than it is to pick the morphologically correct mutation grade. By restricting the domain of CORHOM to the (recursive) prosodic word we see why both $\mathrm{CF}$ and s-fortition apply in compounds, which involve recursive pwords, but neither applies in noncompound complex NPs, which do not involve recursive pwords.

\section{CONCLUSIONS}

Although the lenition mutation of Irish is not a phonological process, as Green (2003) has shown, and the selection of the lenition allomorph is made on purely morphological grounds, not phonological ones, this selection can be overridden by phonological considerations, specifically the desire for a coronal consonant to be followed by another coronoal consonant within the same pword. We have seen how the facts of coronal fusion and s-fortition show that some nominal head + modifier constructions in Irish are compounds involving a recursive pword, such as $\omega_{\omega}\left({ }_{\omega}(\right.$ tonn $) \omega_{\omega}($ tuile $\left.)\right)$ 'tidal wave' and $\omega_{\omega}($ $\omega_{\omega}(\text { scoil })_{\omega}((\mathrm{t})$ saothair $\left.)\right)$ 'industrial school', while other such constructions are not 
compounds, such as ${ }_{\omega}($ foireann $){ }_{\omega}($ Dhoire $)$ ‘the Derry team' and ${ }_{\omega}$ (bean) ${ }_{\omega}$ (Shéamais $)$ 'Séamas's wife'. Thus while left-headed compounds share the morphological property of left-headedness with noncompound head + modifier constructions, they share the prosodic property of recursive pword structure with right-headed compounds. 


\section{REFERENCES}

Ball, Martin J.; Müller, Nicole (1992). Mutation in Welsh. London: Routledge.

Booij, Geert (1988). On the relation between lexical phonology and prosodic phonology. In Certamen Phonologicum, Pier Marco Bertinetto and Michele Loporcaro (eds.), 63-76. Turin: Rosenberg and Sellier.

Christian Brothers (1960). Graiméar Gaeilge. Dublin: An Gúm.

Doyle, Aidan (2001). Irish. Munich: LINCOM EUROPA.

Gnanadesikan, Amalia Elizabeth (1997). Phonology with ternary scales. PhD dissertation, University of Massachusetts. ROA-195, Rutgers Optimality Archive, http://roa.rutgers.edu/.

Green, Antony Dubach (2000). The prosodic representation of clitics in Irish. In Clitics in Phonology, Morphology and Syntax, Birgit Gerlach and Janet Grijzenhout (eds.), 181-218. Amsterdam: John Benjamins.

. (2003). The independence of phonology and morphology: The Celtic mutations. In Papers in Phonology and Phonetics, T. A. Hall and Silke Hamann (eds.), 47-86. ZAS Papers in Linguistics 32. Berlin: Zentrum für Allgemeine Sprachwissenschaft. Also available as ROA-652, Rutgers Optimality Archive, http://roa.rutgers.edu/.

Grijzenhout, Janet (1995). Irish consonant mutation and phonological theory. PhD dissertation, University of Utrecht.

Guerssel, Mohamed (1977). Constraints on phonological rules. Linguistic Analysis 3, $267-305$. 
Hannahs, S. J. (1996). Phonological structure and soft mutation in Welsh. In Interfaces in Phonology, Ursula Kleinhenz (ed.), 46-59. Studia Grammatica 41. Berlin: Akademie Verlag.

Hayes, Bruce (1986). Inalterability in CV phonology. Language 62, 321-52.

Inkelas, Sharon (1989). Prosodic constituency in the lexicon. PhD dissertation, Stanford University. Published New York: Garland, 1991.

Inkelas, Sharon; Cho, Young-mee Yu (1993). Inalterability as prespecification. Language 69, 529-74.

Kibre, Nicholas J. (1995). A model of mutation in Welsh. MA thesis, University of California at Santa Barbara. Distributed by Indiana University Linguistics Club.

Kirchner, Robert (2000). Geminate inalterability and lenition. Language 76, 509-45.

Lieber, Rachel (1987). An Integrated Theory of Autosegmental Processes. Albany: SUNY Press.

Lombardi, Linda (2002). Coronal epenthesis and markedness. Phonology 19, 219-51.

Massam, Diane (1983). The morphology of Irish mutation. MIT Working Papers in Linguistics 5, 10-29.

McCarthy, John J.; Prince, Alan S. (1993a). Generalized alignment. Yearbook of Morphology 1993, 79-153.

(1993b). Prosodic morphology: Constraint interaction and satisfaction. Rutgers University Center for Cognitive Science Technical Report \#3. Revised version (2001) available as ROA-482, Rutgers Optimality Archive, http://roa.rutgers.edu/. 
McHugh, Brian D. (1990). The phrasal cycle in Kivunjo Chaga tonology. In The Phonology-Syntax Connection, Sharon Inkelas and Draga Zec (eds.), 217-42. Chicago: University of Chicago Press.

Murray, Robert W.; Vennemann, Theo (1983). Sound change and syllable structure in Germanic phonology. Language 59, 514-28.

Nespor, Marina; Vogel, Irene (1986). Prosodic Phonology. Dordrecht: Foris.

Ní Chiosáin, Máire (1991). Topics in the phonology of Irish. PhD dissertation, University of Massachusetts.

Ó Siadhail, Mícheál (1989). Modern Irish: Grammatical Structure and Dialectal Variation. Cambridge: Cambridge University Press.

Prince, Alan; Smolensky, Paul (1993). Optimality theory: Constraint interaction in generative grammar. Rutgers University Center for Cognitive Science Technical Report \#2. Revised version (2002) available as ROA-537, Rutgers Optimality Archive, http://roa.rutgers.edu/.

Pyatt, Elizabeth Jane (1997). An integrated model of the syntax and phonology of Celtic mutation. $\mathrm{PhD}$ dissertation, Harvard University.

Schein, Barry; Steriade, Donca (1986). On geminates. Linguistic Inquiry 17, 691-744.

Vennemann, Theo (1988). Preference Laws for Syllable Structure and the Explanation of Sound Change with Special Reference to German, Germanic, Italian, and Latin. Berlin: Mouton de Gruyter. 


\section{NOTES}

1. Hannahs (1996) argues that the environment for some instances of mutation in Welsh is prosodic rather than morphosyntactic.

2. For reasons that cannot be discussed here (because of space limitations), $r$ is excluded from this generalization; coronals after $r$ undergo lenition in the same way as after noncoronal sounds.

3. The assumption that proclitics are incorporated into a recursive pword contradicts the position of Green (2000), who argues that proclitics are not incorporated into any pword in Irish.

4. The standard language permits also don sagart, with CF rather than s-fortition.

5. The surface form [tagərt] cannot correspond to input/hagərt/, because such an analysis would require that the input sequences $/ \mathrm{h} /$ and $/ \mathrm{nh} /$ optimally surface as $[\mathrm{lt}]$ and [nt] in Irish. But in fact such sequences surface faithfully, e.g. fillfidh [f'il'hi:] 'will return', fanfaidh [fanhi:] 'will wait'.

6. Note that $t l-$ is an acceptable onset cluster in Irish, as in tláith [tla:] 'weak' and tlú [tlu:] 'tongs'.

7. In the standard language, where t-initial lenition allomorphs like tsagart appear only after the definite article, the alignment constraint apparently targets the definite article specifically rather than any coronal sonorant. In the dialects with generalized sfortition, the target of the alignment constraint has been broadened to that stated here. 